\title{
Association between the Rs3087243 polymorphism and risk for diabetes: a meta-analysis
}

\author{
J. Liu' ${ }^{1}$ and H.-X. Zhang ${ }^{2}$
}

${ }^{1}$ Shanghai Key Laboratory for Prevention and Treatment of Bone and Joint Diseases with Integrated Chinese-Western Medicine, Shanghai Institute of Orthopaedics and Traumatology, Department of Orthopaedics, Shanghai Ruijin Hospital, Shanghai Jiao Tong University School of Medicine, Shanghai, China ${ }^{2}$ Research Center for Experimental Medicine, State Key Laboratory of Medical Genomics, Shanghai Ruijin Hospital, Shanghai Jiao Tong University School of Medicine, Shanghai, China

Corresponding author: H.-X. Zhang

E-mail: zhang_hongxin@hotmail.com

Genet. Mol. Res. 12 (4): 6344-6350 (2013)

Received November 19, 2012

Accepted August 24, 2013

Published December 6, 2013

DOI http://dx.doi.org/10.4238/2013.December.6.1

ABSTRACT. The aim of this study was to evaluate the association between the rs3087243 polymorphism of the cytotoxic T-lymphocyteassociated antigen-4 (CTLA-4) gene and the risk of type 1 diabetes mellitus (T1D). A comprehensive meta-analysis of case-control studies was conducted to determine the association between the rs3087243 polymorphism $(\mathrm{CT} 60 \mathrm{~A} / \mathrm{G})$ and T1D and assess the joint evidence for the abovementioned association, influence of individual studies, and evidence for publication bias. We searched PubMed, Medline, Embase, Cochrane Library, and reference lists of relevant studies up to February 2012 and contacted the authors of these studies via email. For the case-control studies, 1) the rs3087243 polymorphism was significantly associated with T1D [allele (fixed: odds ratio and 95\% confidence 
interval $(\mathrm{CI})=1.249(1.194-1.307), \mathrm{P}<0.001$; random: odds ratio and $95 \% \mathrm{CI}=1.601(1.103-2.325), \mathrm{P}=0.013)$ ] [genotype $(\mathrm{GG}$ versus $\mathrm{GA}+\mathrm{AA}$ : odds ratio and 95\%CI $=1.249(1.164-1.341), \mathrm{P}<0.001)]$, 2) there was no evidence to show that this association was accounted for in any study, and 3) there was no evidence for publication bias. In conclusion, the rs 3087243 polymorphism was significantly associated with T1D.

Key words: Diabetes; CTLA-4 gene; Meta-analysis; SNPs

\section{INTRODUCTION}

The cytotoxic T-lymphocyte-associated antigen-4 (CTLA-4) gene is located on the long arm of the chromosome 2q33 (Brunet et al., 1987). This gene encodes a receptor expressed by activated $\mathrm{T}$ cells. This receptor functions as a key negative regulator of T-cell activation. Function and experimental data have recommended CTLA-4 as a candidate gene that confers susceptibility to autoimmune disease (Greenwald et al., 2002). In some cases, $\mathrm{T}$ cells that encounter self-antigens may begin to express CTLA-4 molecules as a protective mechanism. CTLA-4 molecules have a high affinity for B7 molecules and deliver inhibitory signals to the T cells. CTLA-4 has a greater affinity for the B7 molecule than CD28, and it downregulates T-cell function (Leung and Linsley, 1994). Therefore, CTLA-4 may play a crucial role in T-cell-mediated autoimmunity and thus in susceptibility to autoimmune diseases, including type 1 diabetes mellitus (T1D).

T1D is the most prevalent form of diabetes in children and young adults and results from autoimmune $\mathrm{CD}^{+}$and $\mathrm{CD} 8^{+} \mathrm{T}$-cell-directed destruction of insulin-producing pancreatic $\beta$-islet cells in genetically susceptible individuals, leading to irreversible hyperglycemia and related complications. Several gene loci have been associated with the risk of developing T1D; among them is IDDM12, which is located on chromosome $2 \mathrm{q} 3$ and encodes key lymphocyte co-receptor genes, including CTLA-4, CD28, and inducible costimulator (ICOS). All these genes are in close linkage (Bartsocas et al. 2006). Many molecular epidemiologic studies have evaluated the potential role of rs3087243 (Ueda et al., 2003; Kawoura and Loannidis, 2005; Zhernakova et al., 2005; Ikegami et al., 2006; Kanazawa et al., 2006; Caputo et al., 2007; Howson et al., 2007) in susceptibility to T1D. Given the amount of accumulated data, we believe that it is important to perform a quantitative synthesis of the evidence. Therefore, we conducted a comprehensive meta-analysis on all available casecontrol association studies.

\section{MATERIAL AND METHODS}

\section{Identification of eligible studies}

A total of 7 references published on the association between the rs 3087243 polymorphism and T1D were identified according to our inclusion criteria, involving 7085 cases and 9963 controls (Zhernakova et al., 2005; Baniasadi et al., 2006; Ikegami et al. 2006; Kanazawa et al., 2006; Howson et al. 2007; Douroudis et al., 2009; Benmansour el al., 2010). The main 
characteristics of these studies are described in Table 1. Sources included MEDLINE and EMBASE (search last updated in February 2012). The search strategy was based on combinations of the terms "CTLA-4", "cytotoxic T-lymphocyte-associated antigen-4", "CD152", and "diabetes". Reference lists in retrieved articles were also screened. We excluded studies with family-based designs in which the analysis was based on linkage (Ueda et al., 2003; Howson et al., 2009).

\section{Data extraction}

The following information was independently extracted from the identified studies by two participants in the meta-analysis: first author, journal, year of publication, study design, ethnicity of the study population, clinical characteristics, genotyping method, the number of cases and controls or odds ratio (OR) and 95\% confidence interval (CI), country in which the study was conducted, and confirmation of diagnosis. The results were compared and any disagreement was discussed and resolved by consensus.

\section{Quality evaluation}

All the studies included 1) discussed the association between the rs 3087243 polymorphism and T1D;2) used disease-free subjects as controls; 3) provided genotype or allele distribution in both case and control groups; 4) were independent studies, without overlap between the subject groups investigated; 5) were published in peer-reviewed journals and indexed by PubMed or cited by articles indexed by PubMed. Authors were contacted where clarification was required.

\section{Statistical analysis}

The meta-analysis examined the overall association of alleles and genotypes and the risk of T1D for the polymorphism. The effect size was represented by an OR with $95 \% \mathrm{CI}$. The Cochran's Q statistical test and the $\mathrm{I}^{2}$ test were used to assess heterogeneity in combined studies. Publication bias was checked using the Begg test, and the Egger test was used for funnel plot asymmetry. Both the random-effect model and the fixed-effect model were used to calculate pooled OR with Woolf's 95\%CI. P values of overall OR were generated using the $Z$ test. Sensitivity analysis was conducted by removing one study at a time and analyzing the others to ensure that no single study was completely responsible for the overall results. The significance level was set at 0.05 , and all $\mathrm{P}$ values were two-tailed. We used inverted funnel plots and the Begg-Mazumdar publication bias diagnostics (nonparametric correlation coefficient) to evaluate whether the magnitudes of the observed associations were related to the variance of each study. The meta-analysis was performed using the Comprehensive Meta Analysis software (Version 2.2.046; BIOSTAT, Englewood, NJ, USA).

\section{RESULTS}

Totally, 7 references met our criteria and 8 studied the rs3087243 polymorphism (Table 1). 
Table 1. Characteristics of the studies included.

\begin{tabular}{|c|c|c|c|c|c|c|}
\hline Study (references) & Year & Country & Racial descent & Polymorphisms & Case & Control \\
\hline Baniasadi et al. & 2006 & India & North Indians & $+49 \mathrm{~A} / \mathrm{G}, \mathrm{CT} 60 \mathrm{~A} / \mathrm{G},-318 \mathrm{C} / \mathrm{T}$ & 130 & 180 \\
\hline Ikegami et al. & 2006 & Japan & Asian & $+49 \mathrm{~A} / \mathrm{G}, \mathrm{CT} 60 \mathrm{~A} / \mathrm{G}$ & 769 & 723 \\
\hline Douroudis-1 et al. & 2009 & Estonia & European & $+49 \mathrm{~A} / \mathrm{G}, \mathrm{CT} 60 \mathrm{~A} / \mathrm{G}$ & 170 & 230 \\
\hline Douroudis-2 et al. & 2009 & Finland & European & $+49 \mathrm{~A} / \mathrm{G}, \mathrm{CT} 60 \mathrm{~A} / \mathrm{G}$ & 404 & 725 \\
\hline Benmansour et al. & 2010 & Tunisia & African & $+49 \mathrm{~A} / \mathrm{G}, \mathrm{CT} 60 \mathrm{~A} / \mathrm{G},-318 \mathrm{C} / \mathrm{T}$ & 228 & 193 \\
\hline Howson et al. & 2007 & Great Britain & European & $\mathrm{CT} 60 \mathrm{~A} / \mathrm{G}$ & 4364 & 6973 \\
\hline Zhernakova et al. & 2005 & India & North Indian & $\mathrm{CT} 60 \mathrm{~A} / \mathrm{G}$ & 350 & 900 \\
\hline Kanazawa et al. & 2006 & Japan & Asian & $\mathrm{CT} 60 \mathrm{~A} / \mathrm{G}$ & 72 & 39 \\
\hline
\end{tabular}

\section{Allelic analysis}

The eligible studies for analysis included 7085 cases and 9963 controls of the rs3087243 polymorphism (Table 1 ). The polymorphism was significantly associated with T1D [fixed: $\mathrm{OR}$ and $95 \% \mathrm{CI}=1.249(1.194-1.307), \mathrm{P}<0.001$; random: $\mathrm{OR}$ and $95 \% \mathrm{CI}=1.601$ (1.103-2.325), $\mathrm{P}=0.013$ ] (Figure 1 and Figure S1).

Study name
Howson 2007
Ikegami 2006
Benmansour 2010
Douroudis-1 2009
Douroudis-2 2009
Baniasadi 2006
Zhernakova 2005
Kanazawa 2006

\begin{tabular}{lllr} 
& \multicolumn{3}{c}{ Statistics for each study } \\
\cline { 2 - 4 } $\begin{array}{c}\text { Odds } \\
\text { ratio }\end{array}$ & $\begin{array}{c}\text { Lower } \\
\text { limit }\end{array}$ & $\begin{array}{c}\text { Upper } \\
\text { limit }\end{array}$ & Z value \\
1.053 & 0.997 & 1.111 & 1.867 \\
3.101 & 2.686 & 3.581 & 15.416 \\
1.669 & 1.214 & 2.294 & 3.155 \\
1.362 & 1.013 & 1.831 & 2.045 \\
1.193 & 0.990 & 1.437 & 1.854 \\
3.780 & 2.791 & 5.119 & 8.594 \\
1.313 & 1.099 & 1.567 & 3.006 \\
0.881 & 0.466 & 1.666 & -0.389 \\
1.249 & 1.194 & 1.307 & 9.640
\end{tabular}

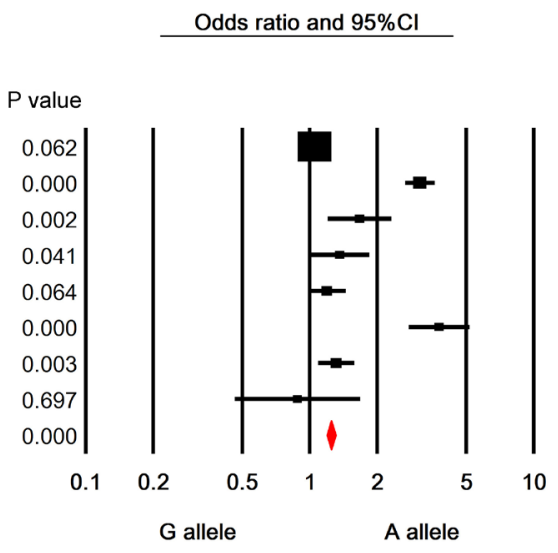

Figure 1. Meta-analysis of association studies of the CT60A/G polymorphism and diabetes (fixed model). Pooled overall OR is shown. The OR of each study is marked with a black square. Pooled OR is indicated by a red diamond.

A sensitivity analysis was conducted, and the results are shown in Figure 2. The sensitivity analysis showed that when any one of the studies was removed, the heterogeneity of the population did not change significantly, indicating that no heterogeneity existed in the population. There was no evidence to prove that the magnitude of the overall OR estimates changed in the same direction over time. Egger's funnel plots of publication bias analysis for the rs3087243 polymorphism are presented in Figure 3.

\section{Genotypic analysis}

For the genotype analysis of rs 3087243 , the result of GG versus GA+AA was significant [OR and $95 \% \mathrm{CI}=1.249(1.164-1.341), \mathrm{P}<0.001$ ], indicating that the GG genotype was deleterious for patients with T1D (Figure 4). 


Study name
Howson 2007
Ikegami 2006
Benmansour 2010
Douroudis-1 2009
Douroudis-2 2009
Baniasadi 2006
Zhernakova 2005
Kanazawa 2006

\begin{tabular}{ccc} 
& \multicolumn{2}{c}{ Statistics with study rem } \\
\cline { 2 - 3 } Point & $\begin{array}{c}\text { Lower } \\
\text { limit }\end{array}$ & $\begin{array}{c}\text { Upper } \\
\text { limit }\end{array}$ \\
1.711 & 1.155 & 2.535 \\
1.451 & 1.103 & 1.909 \\
1.591 & 1.057 & 2.395 \\
1.637 & 1.083 & 2.476 \\
1.670 & 1.076 & 2.592 \\
1.421 & 0.982 & 2.054 \\
1.646 & 1.055 & 2.567 \\
1.708 & 1.150 & 2.536 \\
1.601 & 1.103 & 2.325
\end{tabular}

$Z$ value
2.678
2.659
2.227
2.338
2.286
1.866
2.198
2.654
2.475

$P$ value
0.007
0.008
0.026
0.019
0.022
0.062
0.028
0.008
0.013
Odds ratio $(95 \% \mathrm{Cl})$ with study removed

0.1

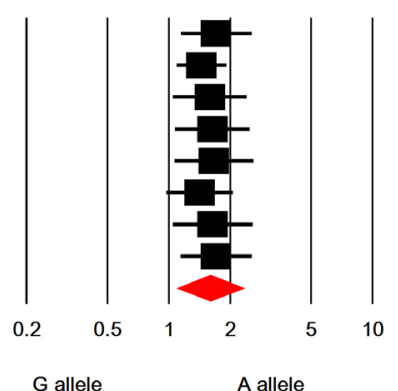

Figure 2. Sensitivity analysis of CT60A/G. When any one of the studies was removed, the heterogeneity of the population remained unchanged.

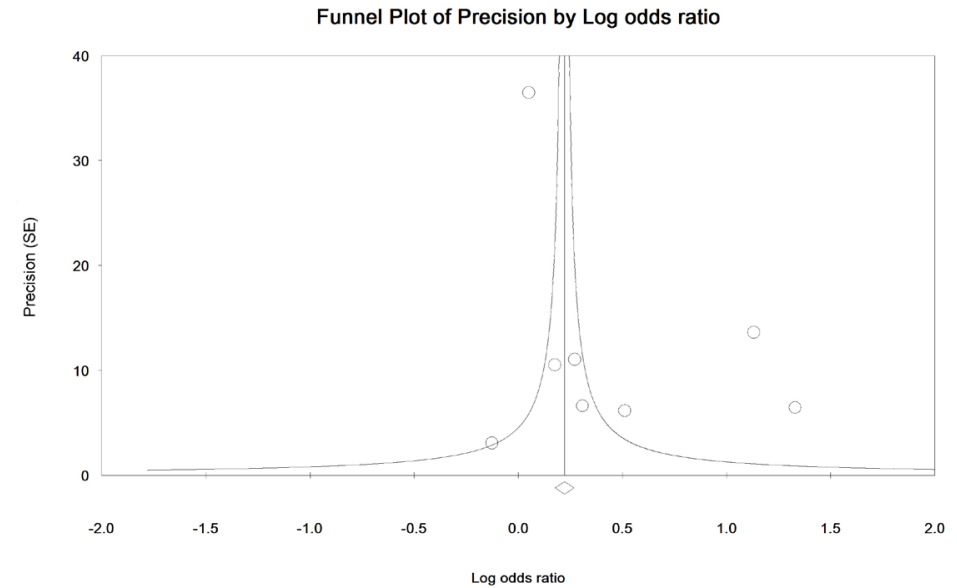

Figure 3. Egger's funnel plots of publication bias analysis for the CT60A/G polymorphism. The larger the deviation from the funnel curve of each study, the more pronounced the asymmetry. Results from small studies scatter widely at the bottom of the graph, with the spread narrowing among larger studies.

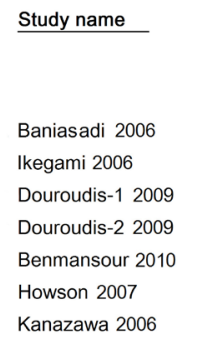

\begin{tabular}{ccccc} 
& \multicolumn{3}{c}{ Statistics for each study } & \\
\cline { 2 - 4 } $\begin{array}{c}\text { Odds } \\
\text { ratio }\end{array}$ & $\begin{array}{c}\text { Lower } \\
\text { limit }\end{array}$ & $\begin{array}{c}\text { Upper } \\
\text { limit }\end{array}$ & Z value & P value \\
1.345 & 0.776 & 2.330 & 1.056 & 0.291 \\
1.182 & 0.960 & 1.455 & 1.572 & 0.116 \\
1.763 & 1.177 & 2.640 & 2.751 & 0.006 \\
1.317 & 1.032 & 1.681 & 2.210 & 0.027 \\
2.374 & 1.183 & 4.762 & 2.433 & 0.015 \\
1.223 & 1.126 & 1.328 & 4.777 & 0.000 \\
1.171 & 0.534 & 2.571 & 0.394 & 0.693 \\
1.249 & 1.164 & 1.341 & 6.170 & 0.000
\end{tabular}

Odds ratio and $95 \% \mathrm{Cl}$

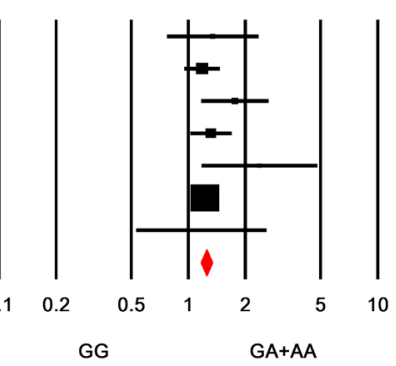

Figure 4. Meta-analysis of association studies of the $\mathrm{CT} 60 \mathrm{~A} / \mathrm{G} \mathrm{GG} /(\mathrm{GA}+\mathrm{AA})$ and diabetes. Pooled overall OR is shown. The OR of each study is marked with a black square. Pooled OR is indicated by a red diamond. 


\section{DISCUSSION}

T1D is commonly considered an organ-specific autoimmune disorder with a multifactorial background, where onset is preceded by a period of autoimmune destruction towards the insulin-producing pancreatic $\beta$-cells and with high levels of IFN- $\gamma$ and TNF- $\beta$ (Atkinson and Eisenbarth, 2001). However, the pathogenesis of the development and progression of T1D is very unclear at present. Because of the various and serious lifelong complications of T1D, identification of the etiologic factors is crucial in the pathogenesis of this disease. The major histocompatibility complex region explains approximately half of the genetic susceptibility to T1D, suggesting that additional determinants exist, and such determinants have been repeatedly suggested by different genome scans (Polychronakos and Li, 2011).

A number of studies indicated that variants of the CTLA-4 gene contribute to the disease. Fine-mapping analyses have also suggested that peak linkage and association are present in the CTLA-4 region [+49A/G, $-819 \mathrm{C} / \mathrm{T}$, and (AT)n in the 3'-UTR] (Marron et al., 1997). However, the results of genetic association studies have been confusing because of the difficulty in replicating significant associations. Different characteristics among studies, such as ethnicities, diabetes mellitus type, definition of case and control, have introduced heterogeneity and made the results of association studies difficult to interpret. This comprehensive metaanalysis included data from 8 studies, with approximately 17048 T1D cases and controls. It revealed significant evidence of the association between the rs 3087243 polymorphism and T1D.

The rs3087243 polymorphism showed an overall association with T1D. The G allele and the GG genotype were positively associated with T1D in the population, implying that rs3087243 may have a significant effect on the disease and may be in linkage disequilibrium with other causative mutations.

In conclusion, the current comprehensive meta-analysis included a large sample size. The design of systematic methods and analytical approaches as well as tests of heterogeneity and sensitivity analyses have produced significant results. Since T1D is caused by the combined actions of many factors, for greater insight into its genetic component, further studies are required to confirm the role of other genes that may have a small individual effect and to identify new genetic risk factors.

\section{ACKNOWLEDGMENTS}

Research supported by grants from the National Natural Science Foundation of China (\#31000408) and the fund from Shanghai Education Committee for young teachers (\#jdy10001).

\section{Supplementary material}

\section{REFERENCES}

\footnotetext{
Atkinson MA and Eisenbarth GS (2001). Type 1 diabetes: new perspectives on disease pathogenesis and treatment. Lancet 358: 221-229.

Baniasadi V, Narain N, Goswami R and Das SN (2006). Promoter region -318 C/ T and -1661 A/G CTLA-4 single nucleotide polymorphisms and type 1 diabetes in North Indians. Tissue Antigens 67: 383-389.

Bartsocas CS and Gerasimidi-Vazeou A (2006). Genetics of type 1 diabetes mellitus. Pediatr. Endocrinol. Rev. 3 (Suppl 3): 508-513.
} 
Benmansour J, Stayoussef M, Al-Jenaidi FA, Rajab MH, et al. (2010). Association of single nucleotide polymorphisms in cytotoxic T-lymphocyte antigen 4 and susceptibility to autoimmune type 1 diabetes in Tunisians. Clin. Vaccine Immunol. 17: 1473-1477.

Brunet JF, Denizot F, Luciani MF, Roux-Dosseto M, et al. (1987). A new member of the immunoglobulin superfamily CTLA-4. Nature 328: 267-270.

Caputo M, Cerrone GE, Mazza C, Cedola N, et al. (2007). No evidence of association of CTLA4 -318 C/T, 159 C/T, 3' STR and SUMO4 163 AG polymorphism with autoimmune diabetes. Immunol. Invest. 36: 259-270.

Douroudis K, Laine AP, Heinonen M, Hermann R, et al. (2009). Association of CTLA4 but not ICOS polymorphisms with type 1 diabetes in two populations with different disease rates. Hum. Immunol. 70: 536-539.

Greenwald RJ, Oosterwegel MA, van der Woude D, Kubal A, et al. (2002). CTLA-4 regulates cell cycle progression during a primary immune response. Eur. J. Immunol. 32: 366-373.

Howson JM, Dunger DB, Nutland S, Stevens H, et al. (2007). A type 1 diabetes subgroup with a female bias is characterised by failure in tolerance to thyroid peroxidase at an early age and a strong association with the cytotoxic T-lymphocyteassociated antigen-4 gene. Diabetologia 50: 741-746.

Howson JM, Walker NM, Smyth DJ and Todd JA (2009). Analysis of 19 genes for association with type I diabetes in the Type I Diabetes Genetics Consortium families. Genes Immun. 10 (Suppl 1): S74-S84.

Ikegami H, Awata T, Kawasaki E, Kobayashi T, et al. (2006). The association of CTLA4 polymorphism with type 1 diabetes is concentrated in patients complicated with autoimmune thyroid disease: a multicenter collaborative study in Japan. J. Clin. Endocrinol. Metab. 91: 1087-1092.

Kanazawa Y, Motohashi Y, Yamada S, Oikawa Y, et al. (2006). Frequency of CTLA-4 gene CT60A/G polymorphism may not be affected by vitamin D receptor gene Bsm I polymorphism or HLA DR9 in autoimmune-related type 1 diabetes in the Japanese. Ann. N. Y. Acad. Sci. 1079: 251-256.

Kawoura F and Loannidis J (2005). CTLA-4 gene polymorphisms and susceptibility to type 1 diabetes mellitus: A HuGE review and meta-analysis. Am. J. Epidemiol. 162: 13-16.

Leung HT and Linsley PS (1994). The CD28 costimulatory pathway. Ther. Immunol. 1: 217-228.

Marron MP, Raffel LJ, Garchon HJ, Jacob CO, et al. (1997). Insulin-dependent diabetes mellitus (IDDM) is associated with CTLA4 polymorphisms in multiple ethnic groups. Hum. Mol. Genet. 6: 1275-1282.

Polychronakos C and Li Q (2011). Understanding type 1 diabetes through genetics: advances and prospects. Nat. Rev. Genet. 12: 781-792.

Ueda H, Howson JM, Esposito L, Heward J, et al. (2003). Association of the T-cell regulatory gene CTLA4 with susceptibility to autoimmune disease. Nature 423: 506-511.

Zhernakova A, Eerligh P, Barrera P, Wesoly JZ, et al. (2005). CTLA4 is differentially associated with autoimmune diseases in the Dutch population. Hum. Genet. 118: 58-66. 